\title{
Radical prostatectomy reduced death from prostate cancer but not all cause mortality
}

\author{
Holmberg L, Bill-Axelson A, Helgesen F, et al. A randomized trial comparing radical prostatectomy with watchful waiting in \\ early prostate cancer. $N$ Engl J Med 2002;347:781-9. \\ Steineck G, Helgesen F, Adolfsson J, et al. Quality of life after radical prostatectomy or watchful waiting. $N$ Engl J Med \\ 2002;347:790-6.

\section{QUESTION: In men with early prostate cancer, is watchful waiting as effective as radical prostatectomy?}

\section{Design} \\ Randomised (allocation concealed*), blinded \{outcome \\ *See glossary. \\ $\dagger$ Information provided by author. \\ Swedish Cancer Society. \\ For correspondence: \\ Dr A Bill-Axelson, \\ University Hospital, \\ Uppsala, Sweden. \\ annabill-axelson@ \\ urology.uas.lul.se and \\ $\operatorname{Dr} G$ Steineck, \\ Karolinska Institutet \\ Stockholm, Sweden. \\ gunnarsteineck@ \\ onkpat.ki.se
} assessors, data analysts, and monitoring committee $\} \uparrow, *$ controlled trial with median 6.2 years of follow up (Scandinavian Prostatic Cancer Group Study Number 4 [SPCG-4]).

\section{Setting}

14 centres in Sweden, Finland, and Iceland.

\section{Patients}

698 men $<75$ years of age with newly diagnosed prostate cancer and tumour stage T0d, T1, or T2. Patients with other cancers or signs of metastases were excluded. 695 men (mean age $65 \mathrm{y}$ ) had complete follow up.

\section{Intervention}

Patients were allocated to radical prostatectomy $(n=347)$ or watchful waiting $(n=348)$. Adjuvant treatment was not given. For local progression, prostatectomy group patients received orchidectomy or gonadotropin releasing hormone analogues and some watchful waiting group patients received transurethral resection.

\section{Main outcome measures}

Death from prostate cancer, distant metastases, local progression, and overall mortality. A subsequent follow up study assessed quality of life outcomes.

\section{Main results}

Analysis was by intention to treat. During follow up, fewer patients in the radical prostatectomy group than the watchful waiting group died from prostate cancer (relative hazard [RH] $0.50,95 \%$ CI 0.27 to 0.91 ) (table), developed distant metastases (RH 0.63, CI 0.41 to 0.96 ), or had local progression (RH 0.31 , CI 0.22 to 0.44 ). The difference between groups for all cause mortality was not statistically significant (RH 0.83 , CI 0.57 to 1.2 ) (table).

Quality of life outcomes were assessed by mailed questionnaire in 326 men $(87 \%$ of the men enrolled between January 1989 and February 1996): More radical prostatectomy patients than watchful waiting patients reported erectile dysfunction $(80 \% v 45 \%$, relative risk [RR] 1.8 , CI 1.5 to 2.2) and urinary leakage (18\% v 2\%, RR 9.3, CI 2.9 to 29.9); groups did not differ for bowel function, psychological wellbeing, or subjective quality of life values.

\section{Conclusions}

In men with early prostate cancer, radical prostatectomy reduced deaths from prostate cancer but did not reduce overall mortality more than watchful waiting. Prostatectomy was associated with more erectile dysfunction and urinary leakage but did not adversely affect self assessed quality of life.
Source of funding:

Radical prostatectomy $v$ watchful waiting for prostate cancer at median 6.2 year follow up $\ddagger$

\begin{tabular}{lllll} 
Outcomes & $\begin{array}{l}\text { Radical } \\
\text { prostatectomy }\end{array}$ & $\begin{array}{l}\text { Watchful } \\
\text { waiting }\end{array}$ & RRR (95\% Cl) & NNT (CI) \\
\hline $\begin{array}{c}\text { Death from } \\
\text { prostate cancer }\end{array}$ & $4.6 \%$ & $8.9 \%$ & $48 \%(8$ to 71$)$ & $24(13$ to 173$)$ \\
\hline All cause mortality & $15 \%$ & $18 \%$ & $14 \%(-20$ to 38$)$ & Not significant \\
\hline
\end{tabular}

†Abbreviations defined in glossary; RRR, NNT, and $\mathrm{Cl}$ calculated from data in article.

\section{COMMENTARY}

The initial results of SPCG-4 indicate that 24 men with clinically detected early prostate cancer would need to be treated with surgery to prevent 1 additional death attributed to prostate cancer over a 6 year period, without evidence that this would improve length or quality of life. The authors cautiously and correctly concluded that longer follow up was needed to clarify whether the benefit increases or decreases over time and whether a survival advantage would follow. This benefit has to be weighed against the side effects of the operation and the lack of demonstrated difference in overall survival. For these reasons we cannot say that radical prostatectomy is better than watchful waiting for all men with localised prostate cancer.

The SPCG-4 results apply most directly to men similar to most of those enrolled in the trial, (ie, healthy men $<75$ years of age with newly diagnosed, clinically detected [as opposed to screen detected] localised prostate cancer that is well or moderately differentiated [Gleason score $\leq 7]$ ). The Veterans Administration Cooperative Urological Research Group (VACURG) compared radical prostatectomy with watchful waiting and showed similar overall survival after a median 23 years of follow up, but the study was too small to determine if important survival differences existed between treatments. ${ }^{1}$

Unlike men enrolled in SPCG-4 and VACURG, most men currently diagnosed with prostate cancer are detected by prostate specific antigen (PSA) screening. In such men the risk of death from prostate cancer may be lower than that observed in SPCG-4. Thus, a benefit of surgery (if it exists) would be less. The time before any potential benefit occurs is likely to be even longer.

Rather than showing that prostate cancer screening saves lives or that one treatment approach is superior to another, SPCG-4 reinforces the importance of providing men with balanced information about the relative risks and benefits of screening and early treatment. ${ }^{2-4}$ The results of ongoing trials evaluating men with screen detected prostate cancer with all cause mortality as the primary endpoint are needed to determine whether screening is effective and if early treatment options improve length and quality of life in these patients. ${ }^{5}$

Timothy J Wilt, MD, MPH Minneapolis VA Center for Chronic Disease Outcomes Research Minneapolis, Minnesota, USA

1 Iversen P, Madsen PO, Corle DK. Radical prostatectomy versus expectant treatment for early carcinoma of the prostate. Twenty-three year follow-up of a prospective randomized study. Scand J Urol Nephrol Suppl 1995;172:65-72. 2 Black WC, Haggstrom DA, Welch HG. All-cause mortality in randomized trials of cancer

screening. Natl Cancer Inst 2002;94:167-73. Harris R, Lohr KN. Screening for prostate cancer: an update on

Partin MR, Wilt TJ. Informing patients about prostate cancer screening: identifying and meeting the challenges while the evidence remains uncertain. Am J Med 2002;113:691-3.

Wilt TJ, Brawer MK. The Prostate Cancer Intervention Versus Observation Trial (PIVOT). Oncology 1997;11:1133-9. 